\title{
O CUIDADO APÓS UM ACIDENTE VASCULAR CEREBRAL: REFLEXÕES DO INDIVÍDUO À SAÚDE PÚBLICA
}

\author{
Gigiane Gindri
}

Irani Iracema de Lima Argimon

Rochele Paz Fonseca

\author{
Programa de Pós-Graduação em Psicologia \\ Pontifícia Universidade Católica do Rio Grande do Sul (PUCRS) \\ Endereço eletrônico: gigiane.gindri@gmail.com
}

\begin{abstract}
Resumo
O acidente vascular cerebral (AVC) é uma doença responsável por várias incapacidades, sendo uma importante causa de dependência e redução da qualidade de vida. Essas dificuldades costumam ter um impacto tanto para o indivíduo que teve o AVC quanto para o grupo familiar. Muitas vezes, as sequelas podem tornar-se permanentes requerendo que os cuidados da fase inicial se estendam e uma pessoa assuma esses cuidados: o cuidador. O presente artigo tem por objetivo refletir sobre o cuidado requerido após um $\mathrm{AVC}$, especialmente quanto às vivências do cuidador de assumir funções para as quais não está preparado, assim como o papel do Sistema de Saúde Pública nas relações com o paciente e o cuidador. Os cuidados realizados relacionam-se ao grau de incapacidade do familiar e geralmente são desempenhados por cuidadores familiares, predominantemente mulheres, esposas ou filhas. A educação em saúde é primordial e contribui para a realização do cuidado com qualidade. É preciso discutir as necessidades dos pacientes, cuidadores domiciliares e profissionais de saúde no âmbito das políticas de saúde pública.
\end{abstract}

Palavras-chave: cuidador, acidente vascular, saúde pública, qualidade de vida. 


\section{O cuidado após um acidente vascular cerebral: reflexões do indivíduo à saúde pública}

A vida vai passando dentro de uma rotina que quando o seu fluxo é quebrado, por todos é referida como normal. O que aconteceu? De repente, ou nem tanto assim, mas traumaticamente com certeza, todos foram acometidos pelo inesperado: "Seu João teve um temido AVC". O termo médico, por si só, tem uma carga mística, mas refere-se a uma doença que possivelmente tenha dado sinais, o Acidente Vascular Cerebral - AVC, também conhecido como derrame ou isquemia.

O monstro de sete cabeças poderia ter sido evitado? Quem é o culpado? Quem vai se responsabilizar, agora? Muitas angústias e, entre elas, a incerteza de sobrevida. São momentos que combinam com filme de drama e terror envolvendo a família de quem sofreu um AVC. O pai estava bem, ao menos em tese, mas acordou sentindo-se estranho, uma dor forte e aguda na cabeça, nem deu tempo de chamar ninguém. A esposa encontra-o caído no banheiro e um copo de água estilhaçado no chão. Foi o estrondo da queda que a fez correr. Grita para o filho, chama o vizinho para levar o marido para o hospital.

João não fala, murmura coisas incompreensíveis para a família. Não movimenta o braço direito, mas com o esquerdo faz gestos de que não consegue falar e tenta mostrar que está consciente. $\mathrm{O}$ filho pede que se acalme, estão chegando, mas todo trajeto é de agitação e de tentativa de falar o que aconteceu. Passados 30 minutos, chegam. A cidade é pequena. Foi rápido, mas vai demorar.

No hospital, emergência superlotada, médicos correndo contra o tempo. Não há leito. O caso é muito grave. Uma maca é improvisada. O médico suspeita de AVC e pede exames. O aparelho não funciona. Não há vaga para transferir o paciente. Sobe para o andar, precisa de cuidados intensivos para monitorar pressão arterial e glicose. Após quatro horas, consegue transferência para a capital. Os exames de neuroimagem são realizados. A tomografia confirma: João teve um AVC do tipo isquêmico.

1 Dados obtidos em: http:// portal.saude.gov.br/portal/ aplicacoes/noticias/default. cfm?pg=dspDetalheNoticia\&id area $=124 \& C O \_N O T I C I A=10817$; http://www.who.int/mediacentre/ factsheets/fs317/es/)
O AVC é uma das doenças que mais matam no mundo. É a maior causa de incapacitação da população na faixa etária superior a 50 anos, sendo responsável por 10\% do total de óbitos, $32,6 \%$ das mortes com causas vasculares e $40 \%$ das aposentadorias precoces no Brasil ${ }^{1}$. Ele pode ser isquêmico ou hemorrágico. $\mathrm{O}$ 
primeiro tipo, AVC isquêmico, corresponde a $80 \%$ dos casos, sendo caracterizado pela interrupção do fluxo sanguíneo para o cérebro por um coágulo (trombo) ou por interrupção de atividade elétrica. Os outros 20\% de casos de AVC são do tipo hemorrágico, caracterizado por uma ruptura do vaso sanguíneo na região encefálica, formando um hematoma (LAVADOS et al., 2007).

Um acometimento grave como o AVC pode ser comparado com a perda de um ente querido. Eventos dessa natureza, por acontecerem de forma dramática e inesperada, afetam profundamente a vida dos indivíduos. Em um curto espaço de tempo, o paciente e seus familiares são arremessados em um turbilhão de fatos, que começam com o início abrupto de uma cefaléia intensa acompanhada por alterações da fala e perda da consciência, a necessidade de ser levado com urgência a um pronto socorro, o som da sirene da ambulância, o temor pela vida da pessoa, etc. Muitos desconhecem que o AVC tem tratamento. Tal tratamento depende da natureza do acometimento e cabe à equipe médica a escolha, envolvendo, em geral, uma equipe multidisciplinar (HACHISNSKI, 2007; MÄDER, 2002). Sem deixar de mencionar os recursos técnicos e humanos.

Nessa situação traumática luta-se contra o tempo diante da dicotomia morte e vida. Os familiares procuram entender o que está acontecendo. De repente, o mundo muda drasticamente, como se aquilo não estivesse ocorrendo, produzindo uma sensação de irrealidade. Nesse momento, são comuns frases do tipo: "eu nunca imaginei que isso pudesse acontecer um dia”, ou então, "a gente acha que essas coisas só acontecem com os outros" (MARCON et al., 2006).

O pior passou. Seu João está vivo, mas nada contente. Chora facilmente. Após uma semana na Unidade de Tratamento Intensivo e 10 dias no quarto, terá alta. Por que ele está tão chateado? Ninguém entende o que ele tenta falar e vai embora de cadeira de rodas.

Os filhos trabalham. Tem o mais moço que mora com os pais, mas trabalha todo o dia e só retorna à noite. Os outros dois são casados. A esposa, que já fica em casa mesmo, é que vai cuidar. A decisão é quase que automática. Ela já esperava, sabia que deveria cuidar do esposo, mas sem ideia do porvir. Quando o papel de cuidador é adotado ou dado a alguma pessoa, geralmente essa sabe pouco sobre as implicações deste papel (CHAGAS, MONTEIRO, 2004; PERLINI, FARO, 2005). 
Mobilizados com a prática profissional junto a pacientes acometidos por lesões neurológicas como o AVC, dedicamos esta reflexão sobre os possíveis responsáveis pelos cuidados do Seu João de agora em diante. Pela complexidade de consequências sociais, emocionais, neurobiológicas e físicas gerais que caracteriza o cuidado após um quadro neurológico súbito desta natureza, cresce a área de pesquisa e de extensão acerca desse tema, como o próprio AVC (HAN, HALEY, 1999; RESTA, BUDÓ, 2004), além de em outros quadros, tal como, nas demências (FREITAS et al., 2008; SENA, GONÇALVES, 2008). O cuidado de doenças crônicas dessa natureza envolve diversos aspectos. Algumas das demandas envolvidas desde o incidente até a reabilitação, pensando as consequências advindas deste sofrimento, bem como os envolvidos mais próximos, a família, e o papel do Estado serão abordadas de modo breve.

Falamos em cuidador. Qual é o seu papel? Seria isso quase uma profissão? O cuidador é quem realiza as ações de cuidado. Em geral, desenvolve tarefas que a pessoa doente não tem condições de realizar, as quais contemplam desde a higiene pessoal até a administração financeira da família, buscando melhorar a saúde e a qualidade de vida da pessoa cuidada (PEDRO, MARCON, 2007; KARSCH, 2003; SENA et al., 2006).

É com o cuidador que os profissionais de saúde costumam manter maior contato. Embora o termo seja empregado no gênero masculino mesmo, o perfil mais comum de quem desempenha essa tarefa é ser do sexo feminino. A esposa, geralmente assume a função, seguida pela filha mais velha. Os filhos, na maioria, participam com tarefas materiais e ajuda externa, como locomoção do paciente (MENDES, 2002; NERI, SOMMERHALDER, 2002).

Chegado o momento da alta, o médico reporta-se ao cuidador do Seu João. É um rito de entrega do paciente. Assim, ele entrega a receita para a esposa que se encontra sozinha com o esposo e que não sabe ler. Constrangida, não fala nada. Ouve atentamente que seu marido teve um derrame, foi muito sério, mas que agora está bem. Então, ela não pode deixar de dar os remédios nos horários certos. Ele deve ter um neurologista na cidade deles. $\mathrm{O}$ doutor sabiamente segue com as orientações até repetir que Dona Joana não se esqueça dos remédios porque Seu João tem risco de ter outro derrame. Ela não aguenta e pergunta se ele não vai ficar bom. 
Talvez questionemos como um profissional de saúde toma uma atitude de passar informações, podendo parecer pouco implicado neste processo de saúde. A formação dos profissionais ainda vem de uma escola de eliminar ou, pelo menos, minimizar a doença. Temos ainda que considerar a inserção na lógica da produção, as condições de trabalho exaustivo e a sobre demanda que dificulta o trabalho das equipes médica, de enfermagem e de outros profissionais como psicólogo, nutricionista, fonoaudiólogo, fisioterapeuta.

Lembrando que o Seu João vai para casa, algumas questões surgem. Como é que se deve cuidar do familiar que teve um derrame? O que precisa ser feito? Muitas dúvidas que Dona Joana não sabe como resolver. Ela não conhece ninguém que tenha vivido isso que aconteceu com o seu marido. Além de dar as medicações, outras estratégias precisam ser utilizadas para o melhor cuidado. Esse conhecimento pode diminuir o estresse do cuidador e favorecer a recuperação do paciente (BOCHI, 2004; CHAGAS, MONTEIRO, 2004).

Faz-se importante refletir sobre a pessoa que assume o papel de cuidador. Uma pessoa é designada a cuidar de outra numa situação de enfermidade, por conta de quatro fatores principais: parentesco, gênero, proximidade física e proximidade afetiva. Em geral, são mulheres próximas ao paciente - esposas, filhas, e mães; em menor número sogras e irmãs - e, frequentemente, residem no mesmo domicílio que o paciente. Ainda que essa não seja propriamente uma decisão consentida por parte dessas mulheres, esse cenário se constrói porque há uma expectativa social, além de uma educação cultural feminina que contribui para que esse papel - de cuidador - seja assumido (BICALHO; LACERDA; CATAFESTA, 2008).

A contrapartida do reconhecimento social da importância das ações dessas pessoas é, entretanto, mínimo e, muitas vezes, inversamente proporcional à expectativa inicial posta sobre os cuidados femininos. Esse alguém que se torna cuidador é na maioria uma figura feminina que tem que abdicar de seu papel profissional e de outras atividades pessoas e sociais para assumir uma função não planejada e, muitas vezes, abdicar de projetos futuros (BICALHO; LACERDA; CATAFESTA, 2008; SENA et al., 2006).

A família pode ter dificuldade na aceitação da incapacidade do paciente e as orientações podem favorecer que tenha metas 
mais realistas. As informações sobre o que é o AVC, causas, sequelas e manejo podem permitir a compreensão do quadro e desmistificação, além de permitir uma parceria na reabilitação (VIANA et al., 2008).

Apenas cobrar que é papel da família cuidar do paciente, apontá-la como responsável pela sua recuperação não é suficiente. É necessária a instrumentalização dos cuidados pelo treino e pela informação. Sendo o cuidador primário (com laços de parentesco) ou secundário (com vínculos profissionais de remuneração), uma capacitação torna-se necessária. Esses subsídios devem ser buscados pelo interessado? Vamos observar que quem precisa deste embasamento do que e como fazer para a recuperação do paciente deve se esforçar para adquirir esta ajuda, independente de seu custo? E quem banca os custos?

O paciente necessita e tem indicação de vários atendimentos para uma melhor recuperação. $\mathrm{O}$ processo de reabilitação após o AVC envolve tratamento medicamentoso, fisioterápico, fonoaudiológico, nutricional, entre outros. Todavia, sua aplicação vai depender do tipo de comprometimento neurológico de cada pessoa. No entanto, para alguns, a fisioterapia, mesmo quando indicada, não é realizada, o paciente fica sem medicação porque está em falta no posto e a família nem tem o valor necessário para ir até o posto, o paciente perde vaga na fonoterapia porque não tem transporte, entre outras situações. Surge a situação do que compete à família e o quanto ela tem acesso às informações e serviços necessários para o familiar.

A família já foi "esclarecida” de que existem várias formas de reabilitação. Por exemplo, no comprometimento motor, há intervenções fisioterápicas de diversas naturezas. Se o paciente tiver alteração na fala, a fonoaudiologia pode ser recomendada, pois há recursos de reabilitação de inúmeras esferas. Como observado, o processo de reabilitação desencadeará profundas mudanças no âmbito familiar, inclusive de papéis, pois o adulto acometido por um AVC pode passar de uma postura mantenedora e provedora para outra na qual precisará de suporte e apoio familiar, não só para ser mantido e ter estímulo para realizar o tratamento, como também para desenvolver atividades, outrora simples, em decorrência do déficit motor.

O convívio contínuo com um familiar que tem doença crônica, como aquele que apresenta incapacidades pós-AVC e necessita atenção contínua, pode ter impacto negativo, dependendo de como o cuidador lida com as demandas dessa função (BOCHI, 
2004). A sobrecarga física é decorrente do grau de dependência dos doentes, enquanto que a psicológica guarda relação com o estresse, a ansiedade em relação ao futuro e a restrição das perspectivas de vida. $\mathrm{O}$ impacto na qualidade de vida dos cuidadores pode ser decorrente da sobrecarga de trabalho, da diminuição da renda familiar em virtude da doença, da limitação das atividades sociais e de lazer, bem como precipitadora de alterações na saúde dos cuidadores.

Outro fator que contribui para a sobrecarga e o desgaste do cuidador está relacionado à postura fragmentada dos profissionais de saúde que focalizam o cuidado e direcionam as orientações e informações ao doente crônico e não se preocupam com o cuidador que realiza as atividades e que também tem necessidades de lazer, descanso e afeto. Infelizmente, muitas vezes em vez de ser valorizado e estimulado pelas atividades que desempenha, ele sofre cobranças e críticas nem sempre construtivas em relação a essas ações. $\mathrm{O}$ cuidado domiciliar exige, além de boa vontade e disposição, habilidades e conhecimentos que o instrumentalizem para que se efetive de forma adequada (BOCHI, 2004). Entretanto, a maioria do cuidadores não recebe nenhuma orientação para realizá-lo, sendo suas maiores preocupações o medo em relação às complicações e à agudização do quadro do seu familiar (SOUZA et al., 2006). Ainda pode haver dificuldades para realização de cuidados corporais diários e à falta de materiais, tais como fraldas e medicações. Assim, pode se observar o "caráter solitário“ de quem presta o cuidado domiciliar, especialmente, quando recebe pouca ajuda por parte da família, igreja, vizinhos, amigos e dos serviços de saúde (SENA et al., 2006; PEDRO, MARCON, 2007).

Nesse meandro, vale ressaltar que o cuidado do doente no domicílio acarreta várias mudanças, na vida do cuidador e da família, que interferem na dinâmica familiar. Uma dessas mudanças, enfrentadas pela família, está relacionada à vida social, com a diminuição do convívio social do cuidador, decorrente da nova função assumida, o que acarreta, muitas vezes, a inversão de papéis na estrutura familiar resultante da doença. Outra mudança diz respeito à necessidade de adaptação do ambiente físico com a finalidade de facilitar o cuidado e proporcionar conforto e segurança ao familiar doente. Ocorrem, ainda, perdas econômicas pelo aumento dos gastos e, muitas vezes, pela perda ou desistência do emprego do cuidador (SILVEIRA; CALDAS; CARNEIRO, 2006). 
Todas essas questões apontadas refletem a importância e a necessidade dos profissionais de saúde oferecerem suporte técnico, acompanhamento e orientação constantes aos cuidadores familiares. Além das ações e atividades relacionadas à doença, espera-se que os profissionais de saúde considerem os aspectos emocionais, sociais, inerentes ao contexto de cada família cuidada.

Então chega um momento em que a família não consegue mais lidar com a situação e procura um asilo, também conhecido, como residência ou clínica geriátrica, para o pai. Não tem como manter um enfermeiro em casa. São as crianças para atender, a necessidade de trabalhar, não dá para deixá-lo só. É uma esperança de paz e de que lá ele seja melhor cuidado. O coitado até já está querendo, sentindo-se motivo de desavenças e tão limitado (FALCÃO et al., 2004).

As instituições de moradia para pessoas incapacitadas são alternativas utilizadas por alguns familiares devido à dificuldade de lidarem com os altos níveis de sobrecarga no cuidado de seus entes queridos. Esse quadro pode acontecer em pacientes após o AVC. Além da dependência física, são as mudanças comportamentais as maiores precipitadoras de estresse para os cuidadores (HACHISNSKI, 2007).

Algumas pessoas, geralmente profissionais da saúde, envolvidas na recuperação e qualidade de indivíduos com doenças crônicas, em conjunto com familiares, formam grupos e ONGs. Há poucas associações e ONGs quando comparadas a outras doenças como Diabetes, demência do tipo Parkinson, etc, talvez pela natureza do acometimento e pela demanda que acarreta aos envolvidos. A ONG Rede Brasil AVC é um exemplo desta atuação (CABRAL, 2009).

O Projeto Nacional de Atendimento ao Acidente Vascular Cerebral iniciou em 2008 com o objetivo de implementar um programa de atendimento ao paciente pós-lesão cerebral vascular, visando a contemplar todos os níveis de atenção à saúde: reconhecimento da população, atendimento pré-hospitalar, hospitalar, reabilitação e prevenção. Este projeto da Coordenação Geral de Urgência e Emergência do Ministério da Saúde e da ONG Rede Brasil AVC que inicialmente dava esperanças, surpreende quando os aspectos financeiros não estão como acordados. Para exemplificar, não há verba para a medicação trombolítica no tratamento precoce do AVC isquêmico, quando o evento ocorreu há até três horas. Com o tratamento trombolítico, há até $40 \%$ de 
chances de recuperação funcional total, que quando não ocorre, reduz de modo relevante as sequelas (CABRAL, 2009). No entanto, há falta de trombolítico em hospitais credenciados pelo Sistema Único de Saúde - SUS.

Como pode deixar de ser prioridade este investimento quando a sua ausência demandará cuidados maiores e mais intensos com custos muitas vezes até maiores? Quem lucra com essa atitude? O "montante" não é gasto pelo Estado em um curto espaço de tempo. Entretanto, o paciente precisará de cuidados que necessariamente pressupõem investimento. Se ele não puder retornar ao labor, haverá o auxílio doença, que exemplifica ônus aos cofres públicos.

O cuidador de um lado e o sistema de gestão da saúde do outro, sendo que o primeiro segue na busca constante de um auxílio do segundo. Dedicamos esta reflexão especialmente para aqueles que mais precisam de acesso à saúde como um direito de todos e que tem um familiar que foi acometido por um AVC.

Do ponto de vista do indivíduo que teve um AVC, que está sofrendo e doente, que possivelmente não possa manifestar seu desejo, que se sente mal e tem dificuldades de pedir ajuda, como fica seu direito pela saúde? Ele é um cidadão brasileiro. O Seu João continua sendo um ser humano, não é o AVC isquêmico, nem mais um número na estatística epidemiológica crescente ou um número de leito ou de maca improvisada nos corredores de um hospital.

Lembremos que a Declaração Universal dos Direitos Humanos, nos idos de 1948, já estabeleceu que "toda pessoa tem direito a um padrão de vida capaz de assegurar a si e a sua família saúde e bem-estar, inclusive alimentação, vestuário, habitação, cuidados médicos e os serviços sociais indispensáveis, e direito à segurança em caso de desemprego, doença, invalidez, viuvez, velhice ou outros casos de perda dos meios de subsistência fora de seu controle". Bem se vê, pois, que a preocupação com a saúde e com a qualidade de vida em caso de doença ou invalidez não é recente.

Nesta linha, no Brasil, a Constituição de 1988 reforça esse direito básico do cidadão ao estabelecer, em seu artigo 196, que "a saúde é direito de todos e dever do Estado, garantido mediante políticas sociais e econômicas que visem à redução do risco de doença e de outros agravos e ao acesso universal e igualitário às ações e serviços para sua promoção, proteção e recuperação”. O 
SUS é um dos mecanismos criados pelo Estado para garantir a efetividade desse direito fundamental do cidadão, a saúde. A Lei Orgânica da Saúde, Lei no 8.080/1990, destaca que:

[...] garantir a saúde consiste na formulação e execução de políticas econômicas e sociais que visem à redução de riscos de doenças e de outros agravos, e no estabelecimento de condições que assegurem acesso universal e igualitário às ações e aos serviços para a sua promoção, proteção e recuperação. (BRASIL, 1990).

Observa-se que o sistema de proteção à saúde objetiva garantir esse direito fundamental mediante políticas públicas de promoção, de proteção e, em especial, de recuperação da saúde. Encontramos respaldo legal para Seu João e todos os cidadãos brasileiros, embora ainda mais no campo ideal do que real.

Como está sendo exercido o papel do Estado se o que acompanhamos são emergências superlotadas, falta de leitos hospitalares, sucateamento dos equipamentos, equipe de saúde reduzida para a demanda de pacientes, insuficiência no número de medicamentos, tempo de espera prolongado para atendimento? A história de Seu João e de Dona Joana personifica muitas tristezas, restrições e desafios vivenciados na realidade da saúde pública. Com certeza é questionável se "o acesso universal e igualitário para promoção, proteção e recuperação a saúde” está sendo garantido.

Mas vamos mais adiante. O AVC aconteceu, "a saúde foi roubada", o que pode ser recuperado? Em saúde, o termo recuperação deve ser empregado com todo cuidado. Ainda que os melhores programas de reabilitação, com profissionais e tecnologia de ponta fossem empregados, é pouco provável retornar ao estado pré-mórbido (prévio ao AVC). Como será de agora em diante? Seu João poderá ter acesso a um programa de reabilitação nas especialidades de que necessita?

A reabilitação envolve ações desenvolvidas para a prevenção da deformidade física, manutenção da função física, restabelecimento dessa função, educação do paciente e da família, e reintegração da pessoa à sua família e à sociedade. Desta forma, está relacionada a uma equipe interdisciplinar, composta de médicos, enfermeiros, fonoaudiólogos, psicólogos e fisioterapeutas, além do paciente, foco dos esforços da equipe. Enfatiza-se, também, a importância da família, que desempenha um papel marcante e cuja incorporação propicia mais capacidade de adaptação à mudança de todo o sistema familiar. Aproveitamos 
a retomada do tópico família para salientar que ela é parte do processo, não a única responsável.

$\mathrm{O}$ aumento da expectativa de vida mundial, juntamente com a carência de serviços que atendam casos de AVC no Brasil, fazem com que esse quadro neurológico ou fenômeno biopsicossocial seja quase uma epidemia. Atualmente o AVC é a principal causa de prejuízo funcional no mundo, inclusive no Brasil (LAVADOS et al., 2007). Nesse novo contexto, o portador de AVC necessita de uma série de medidas planejadas e desenvolvidas com vistas a lhe facultar a maior integralidade possível. Como procedimento essencial nesse processo sobressai-se a realização de ações para a reabilitação dos déficits neurológicos surgidos (MATEER; SOHLBERG, 2003).

Segundo a Organização Mundial da Saúde, a reabilitação neuropsicológica não tem o objetivo da cura, visto a gravidade das sequelas neurológicas. A reabilitação objetiva promover a melhor adaptação social, física e psicológica possível do paciente, aplicando-se medidas que reduzam o impacto da inabilidade e condições de desvantagem. Nesse sentido, a família pode ser parceira na atuação interdisciplinar.

Mas como efetivar e garantir essa reabilitação a todo cidadão brasileiro? Surge, então, um problema. Sabe-se que o Brasil é um país em desenvolvimento e, como consequência, limitações de ordem orçamentária podem impedir ou retardar a implementação de algumas políticas públicas. Com as questões de saúde não é diferente, sendo corrente no noticiário a existência de problemas no âmbito do SUS, como carência de recursos, de medicamentos, de médicos, deficiências nos atendimentos, dentre outros. Certamente em função disso tem havido uma judicialização dessas questões, sendo muito comum o ajuizamento de ações em que os cidadãos postulam, perante o Judiciário, o fornecimento de medicamentos ou, até, a realização de tratamentos médicos, muitos deles experimentais.

Essa questão gera grande polêmica. Há quem defenda que, em razão das limitações orçamentárias, não há como exigir, judicialmente ou não, que o Estado preste todo e qualquer serviço ou tratamento de saúde. Nesse sentido podemos citar recente decisão proferida pelo Superior Tribunal de Justiça, o qual decidiu que "O entendimento de que o Poder Público ostenta a condição de satisfazer todas as necessidades da coletividade ilimitadamente, seja na saúde ou em qualquer outro segmento", é utópico; pois o 
aparelhamento do Estado, ainda que satisfatório aos anseios da coletividade, não será capaz de suprir as infindáveis necessidades de todos os cidadãos. Esse cenário, como já era de se esperar, gera inúmeros conflitos de interesse que vão parar no Poder Judiciário, a fim de que decida se, nesse ou naquele caso, o ente público deve ser compelido a satisfazer a pretensão do cidadão. $O$ Poder Judiciário, certo de que atua no cumprimento da lei, ao subtrair da alçada da Administração Pública, cria problemas de toda ordem, como desequilíbrio de contas públicas, o comprometimento de serviços públicos, dentre outros.

$\mathrm{O}$ art. $6^{\circ}$ da Constituição Federal, que preconiza a saúde como direito social, deve ser analisado à luz do princípio da reserva do possível, ou seja, os pleitos deduzidos em face do Estado devem ser logicamente razoáveis e, acima de tudo, é necessário que existam condições financeiras para o cumprimento de obrigação. De nada adianta uma ordem judicial que não pode ser cumprida pela Administração por falta de recursos (Recurso Ordinário no Mandado de Segurança no 28.962, Relator Ministro Benedito Gonçalves, publicada no Diário da Justiça de 03/09/2009).

Esse pensamento, no entanto, demonstra uma preocupação ligada unicamente à condição financeira do país. Um país, ou melhor, o Estado não é um ente suficiente em si, com existência própria, independente de seus cidadãos. O Estado só existe porque, antes, existem seres humanos que se agrupam e se organizam para buscar o bem comum. Nessa organização são eleitas prioridades, e uma delas, e a mais importante, é a proteção da vida e da saúde, prioridades essas alçadas ao posto de direitos e garantias fundamentais. Ademais, a saúde é uma garantia fundamental do cidadão brasileiro, pois assim está previsto na Constituição Federal.

Por isso, se há alguma limitação orçamentária, ela nunca deverá ser invocada para negar tratamento de saúde ao cidadão. Ainda, a reabilitação não deve ficar limitada ao simples tratamento medicamentoso ou cirúrgico, meramente à atenção em nível terciário à saúde. Deve ser um tratamento amplo que permita o completo restabelecimento da condição física do cidadão, o que, conforme a gravidade ou tipo de doença que acomete o paciente, envolverá terapia psicológica, fonoaudiológica, fisioterápica, nutricional, dentário, dentre outros.

Negar o direito à saúde é negar o direito a uma vida digna, é negar a própria vida. Negar o direito à saúde devido a uma 
questão orçamentária é equiparar a saúde e a vida do cidadão a alguns poucos dólares ou reais. Por questões orçamentárias, negar um tratamento completo ao Seu João, incluindo tratamento médico, psicológico, fonoaudiológico, fisioterápico, entre outros que eventualmente sejam necessários, é negar o seu direito à vida. Em outras palavras, é declarar sua morte. Afinal, o que vale mais, alguns dólares ou centavos a mais no orçamento do Estado ou a vida e a saúde do Seu João e um contexto mais promissor para o cuidado exercido por Dona Joana?

\section{Referências}

ASSEMBLEIA GERAL DAS NAÇÕES UNIDAS. Declaração Universal dos Direitos Humanos. Paris, 1948.

BICALHO, Cleide Straub; LACERDA, Maria Ribeiro; CATAFESTA, Fernanda. Refletindo quem é o cuidador familiar. Cogitare Enfermagem, Curitiba, v. 13, n. 1, p. 118-123, mar. 2008.

BOCHI, Silvia Cristina Mangini. Vivenciando a sobrecarga ao vir-a-ser um cuidador familiar de pessoa com acidente vascular cerebral (AVC): uma análise do conhecimento. Revista Latino-Americana de Enfermagem, Ribeirão Preto, v. 12, n. 1, p. 115-21, 2004.

BRASIL. Constituição da República Federativa do Brasil, de 05 de outubro de 1988. Disponível em: <http://www.planalto.gov.br>. Acesso em: 28 nov. 2009.

Lei no 8.080, de 19 de setembro de 1990. Disponível em: <http://www.planalto.gov.br>. Acesso em: 28 nov. 2009.

Ministério da Saúde. Projeto Nacional e os resultados do Piloto. Brasília: MS/Secretaria de Atenção à Saúde, ONG Rede Brasil AVC. Disponível em: <http://pwweb2.procempa.com.br/pmpa/prefpoa/ redebrasilavc/usu_doc/resultadosprojetonacional.pdf>. Acesso em: 29 nov. 2009.

. Superior Tribunal de Justiça. Recurso Ordinário no Mandado de Segurança no 28.962, da 1a Turma. Relator: Ministro Benedito Gonçalves. Brasília, DF, 03 de setembro de 2009. Disponível em: <www.stj. jus.br>. Acesso em: 29 nov. 2009.

CABRAL, Norberto Luiz. Epidemiologia e impacto da doença cerebrovascular no Brasil e no mundo. ComCiência Revista Eletrônica de Jornalismo Científico, Especial AVC Acidente Vascular Encefálico, n. 
CHAGAS, Natália Rocha; MONTEIRO, Ana Ruth Macedo. Educação em saúde e família: o cuidado ao paciente, vítima de acidente vascular cerebral. Acta Scientiarum: Health Science, Maringá, v. 26, n. 1, p. 193-204, 2004.

FALCÃO, Ilka Veras; CARVALHO, Eduardo Maia Freese de; BARRETO, Kátia Magdala Lima; LESSA, Fábio José Delgado; LEITE, Valéria Moura Moreira. Acidente Vascular Cerebral precoce: implicações para adultos em idade produtiva atendidos pelo Sistema Único de Saúde. Revista Brasileira de Saúde Materno Infantil, Recife, v. 4, n. 1, p. 95-101, 2004.

FREITAS, Iara Cristina Carvalho; PAULA, Kelvia Coelho Campos de; SOARES, Juliana Lima; PARENTE, Adriana da Cunha Menezes. Convivendo com o portador de Alzheimer: perspectivas do familiar cuidador. Revista Brasileira de Enfermagem, Brasília, v. 61, n. 4, p. 508-13, jul./ago. 2008.

HAN, Beth; HALEY, William E. Family Caregiving for Patients With Stroke: Review and Analysis. Stroke, v. 30, p. 1478-1485, 1999. Disponível em <http://stroke.ahajournals.org/cgi/content/full/30/7/1478>. Acesso em: 30 dez. 2009.

HACHISNSKI, Vladimir. Stroke and vascular cognitive impairment: a transdisciplinary, translational and transactional approach. Stroke, v. 38, pp. 1396-1403, 2007.

KARSCH, Ursula M. Idosos dependentes: famílias e cuidadores. Cadernos de Saúde Pública, Rio de Janeiro, v. 19, n. 3, p. 861-6, mai./jun. 2003.

LAVADOS, Pablo M.; HENNIS, Anselm J. M.; FERNANDES, Jefferson G.; MEDINA, Marco T.; LEGETIC, Branca; HOPPE, Arnold; SACKS, Claudio; JADUE, Liliana; SALINAS, Rodrigo. Stroke epidemiology, prevention, and management strategies at a regional level: Latin America and the Caribbean. Lancet Neurology, v. 6, p. 362-72, 2007.

MÄDER, Maria Joana. Avaliação neuropsicológica: da pesquisa à prática clínica com adultos. In: CRUZ, Roberto Moraes; ALCHIERI, João Carlos; SARDA JR, João Carlos. Avaliação e medidas psicológicas: produção do conhecimento e da intervenção profissional. São Paulo: Casa do Psicólogo; 2002. p. 47-68. 
MATEER, Catherine A.; SOHLBERG, McKay Moore. Cognitive rehabilitation revisited. Brain Impairment, v. 4, n. 1, p. 17-24, 2003.

MARCON, Sonia Silva; LOPES, Mislaine Casagrande; ANTUNES, Claúdia Regina Marchiori; FERNANDES, Jandira; WAIDMAN, Maria Angelica Pagliarini. Famílias cuidadoras de pessoas com dependência: um estudo bibliográfico. Online Brazilian Journal of Nursing, Rio de Janeiro, v. 6, n. 1, 2006. Disponível em: <http://www.uff.br/objnursing/index.php/nursing/rt/printerFriendly/653/

153.> Acesso em: 25 nov. 2009.

MENDES, Patrícia. Brand Mourão Teixeira. Quem é o Cuidador. In: DIAS, Ernesta Lopes Ferreira; WANDERLEY, Jamiro da Silva ; MENDES, Roberto Teixeira . Orientações para cuidadores informais na assistência domiciliar. Campinas, Unicamp, 2002. p.17-30.

MINISTÉRIO DA SAÚDE/SE/DATASUS - Banco de Dados. Disponível em: <http://portal.saude.gov.br/portal/aplicacoes/noticias/default.cfm?pg=dspDetalheNoticia\&id_area=124\&CO_NOTICIA=10817>. Acesso em: 29 nov. 2009.

NERI, Anita Liberalesso; SOMMERHALDER, Cinara. As várias faces do cuidado e do bem-estar do cuidador. In: NERI, Anita Liberalesso. (Org.). Cuidar de idosos no contexto da família: questões psicológicas e sociais. Campinas, Alínea, 2002.p. 9-63.

ORGANIZAÇÃO MUNDIAL DA SAÚDE OMS/WHO. Enfermidades Cardiovasculares. Disponível em: <http://www.who.int/mediacentre/factsheets/fs317/es/>. Acesso em: 29 nov. 2009.

PEDRO, Karina Santo; MARCON, Sonia Silva. Perfil e vivência dos cuidadores informais de doentes crônicos assistidos pelo NEPAAF - Núcleo de estudos, pesquisa, assistência e apoio à família. Online Brazilian Journal of Nursing, Rio de Janeiro, v. 6, n. 0, 2007. Disponível em: <http://www.uff.br/objnursing/index.php/nursing/article/ view/653/153>. Acesso em: 25 nov. 2009.

PERLINI, Nara Marilene Oliveira Girardon; FARO, Ana Cristina Mancussi . M. Cuidar de pessoa incapacitada por acidente vascular cerebral no domicílio: o fazer do cuidador familiar. Revista da Escola de Enfermagem da USP, São Paulo, v. 39, n. 2, p. 154-63, jun. 2005.

RESTA, Darielli Gindri; BUDÓ, Maria de Lourdes Denardin. A cultura e as formas de cuidar em família na visão de pacientes e cuidadores domiciliares. Acta Scientiarum: Health Science, Maringá, v. 26, n. 1, p. 53-60, 2004. 

Ferreira; VIVAS, Karine Lara; QUEIROZ, Carla Mendes; BARRETO; Fernanda Ourives. O cotidiano da cuidadora no domicílio: desafios de um fazer solitário. Cogitare Enfermagem, Curitiba, v. 11, n. 2, p. 124-32, 2006.

SENA, Edite Lago da Silva; GONÇALVES, Lucia Hisako Takase. Vivencias de familiares cuidadores de pessoas idosas com doença de Alzheimer- perspectiva da filosofia de Merleau-Ponty. Revista Texto e Contexto Enfermagem, Florianópolis, v. 17, n. 2, p. 232-40, abr./jun. 2008.

SILVEIRA, Teresinha Mello da; CALDAS, Célia Pereira; CARNEIRO, Terezinha Féres. Cuidando de idosos altamente dependentes na comunidade: um estudo sobre cuidadores familiares principais. Cadernos de Saúde Pública, Rio de Janeiro, v. 22, n. 8, p. 1629-38, 2006.

SOUZA, Wanusa Grasiela Amante de; PACHECO, Wladja Nara Sousa; MARTINS, Josiane de Jesus;BARRA, Daniela Couto Carvalho; NASCIMENTO, Eliane Regina Pereira do. Educação em saúde para leigos no cuidado ao idoso no contexto domiciliar. ACM: Arquivos Catarinenses de Medicina, Florianópolis, v. 35, n. 4, p. 56-63, 2006.

VIANA, Fabiana Pavan; LORENZO, Anapaula Castro de; OLIVEIRA, Érika Felipe de; RESENDE, Selma MendeS. Medida de independência funcional nas atividades de vida diária em idosos com seqüelas de acidente vascular encefálico no Complexo Gerontológico Sagrada Família de Goiânia. Revista Brasileira de Geriatria e Gerontologia, Rio de Janeiro, v.11 , n.1, 2008. Disponível em: <http://www.unati. uerj.br/tse/scielo.php?script=sci_arttext\&pid=S1809-9823200800010 0003\&lng=pt\&nrm=iso >. Acesso em: 29 nov. 2009. 
Abstract

Cerebrovascular accident (CVA) is a disease responsible for various incapabilities, being a major cause of dependence and reducing the quality of life. These difficulties often have an impact both for the individual who had the stroke and for the family group. Often, the consequences can become permanent requiring an extended care of the initial phase and a person to take such care: the carer. This article aims to reflect on the care required after a stroke, especially on the experiences of the caregiver to assume tasks for which he is prepared as well as the role of the Public Health System in relations with the patient and the caregiver. The care given is directly related to the degree of incapacity of the person who is being cared for, carried out mainly by devoted family caregivers, most of them women, wives or daughters. The education in health is primordial and contributes for the accomplishment of the care with quality. It needs to discuss the necessities of the patients, caregivers and health professionals issue in the realm of public policies

Keywords: caregiver, stroke, public health, quality of life. 
